Stewart, S. (2014). Aesthetics and Time: Sustained and Distracted Modes of Engagement. Cultural Sociology. doi:10.1177/1749975514557549

\title{
Aesthetics and Time: Sustained and Distracted Modes of Engagement
}

\section{Introduction}

In its aim to contribute towards a better understanding of the ways in which people engage with and evaluate cultural objects, this article considers the relation between aesthetic engagement and time. Aesthetic engagement is an active process, a tangle of spontaneity and probability, a commingling of attachments and determinisms that needs to be understood in relation to the past and the present. This article puts forward a sociologically-based approach to considering social time and its stratifications, and more specifically, two intersecting temporal dimensions of aesthetic engagement: the sweep of time that leads to the moment of engagement and the particular moment of engagement itself. The sweep of time needs to be explored because individuals, in common with the cultural objects with which they engage, have histories and trajectories which when plotted over time take stable but sometimes relatively unpredictable courses. Zooming in on the particular moment of aesthetic engagement in its sustained and distracted modes will enable us to better understand the extent of engagement as other objects and tasks compete for our attention. A consideration of social time also provides insight into why it is that some are more able than others to possess the time necessary for aesthetic engagement in its sustained mode.

\section{Bourdieu and the 'new' sociology of culture}


There is a growing body of research in sociology that addresses issues of aesthetics and taste (see, for example, Harrington 2008; De La Fuente 2008; Stewart 2012, 2013a, 2013b; Wolff 2008). Much of the research in this field is influenced by the work of the French Sociologist Pierre Bourdieu, though it has been suggested that his social constructionist approach has been superseded by a new sociology of culture (see Nick Prior's (2011) useful literature review on this topic). Sociological approaches to art, with the likes of Bourdieu and Becker at the forefront, have brought art and culture down to earth, stripping them of their mystical qualities and situating them historically and socially. However, beyond their probing of structural determinants and power relations, these approaches have paid scant attention to matters of aesthetics. For example, Howard Becker's (1982) approach to art-worlds is avowedly social-organizational rather than aesthetic. According to Bourdieu (2000: 73), the ability to perceive cultural objects, whether artworks or items of home furnishing, in terms of form rather than function, is characteristic of an aesthetic disposition which depends on two key conditions: first is the emergence, through a long and protracted process, of an artistic field which is, in its most autonomous region, freed from economic and political restraint. The second is the ability of some, as a consequence of their distance from necessity and the privileges associated with their family background and education, to develop a 'pure disposition' (Bourdieu 1984, 2000). Time is central to both of these conditions: the first is concerned with development of the artistic field over time; the second is concerned with the extent to which individuals possess the time to make gratuitous and disinterested investments in culture and to cultivate a habitus aligned with legitimate culture. However, as we will see below, there are limits to these insights as Bourdieu is preoccupied with the symbolic dimension of aesthetics. He does not consider, in any detail, precisely how 
we engage with cultural objects, over time, from time to time, in focused or distracted ways. Therefore, this paper aims to expand the number of different modes of time with which cultural sociologists should engage in order to gain a more fine-grained understanding of the relation between aesthetic engagement and time.

In recent years, Bourdieu's constructionist approach to taste has come under attack from a range of scholars who share the belief that questions of aesthetic value are not entirely reducible to social determinants (DeNora, 1999, 2000; Harrington, 2004; Latour, 2005). One of those at the forefront of this 'new sociology of culture', Antoine Hennion $(2001,2004,2007)$ rejects Bourdieu's 'critical sociology' because, he perceives, it fails to take seriously the cultural practices of individuals. Hennion (2001: 3) argues that in critical sociology, individuals are reduced to their socioprofessional categories and cultural objects are merely passive goods considered only in terms of 'the differential degree of education' required to understand them. Hennion's critique of Bourdieu has much in common with Nicholas Garnham's (1993), which holds that Bourdieu reduces all social action to symbolic power struggles. Bourdieu, according to Hennion (2001, 2004, 2007), restricts his understanding of cultural preferences and passions to strategic moves in wider games of social distinction. In this model, the act of tasting is a mechanical, largely unconscious process, driven by habitus and determined in great part by class background. Cultural objects are merely tokens in a bid for prestige in symbolic struggles, and critical sociology fails to account for the ways in which cultural objects (such as pieces of music) become 'organizing materials of subjectivity' (DeNora 1999: 31). If the 'taster' or the 'amateur', through meticulous planning, corporeal training, and the development of experiments and techniques, takes the time to be attentive to the object's qualities, '[t]he object also advances, takes its time, unfurls 
and exhibits itself' (Hennion 2007: 108). Tasting is, for Hennion, an active, conscious process, even if, in the act of tasting, the taster seeks to be carried away and engulfed in a sense of passion or beauty. For the amateur willing to be carried away or enraptured, this is, then, a passivity actively sought. This is because taste is a coproduction between subject and object (Hennion 2007). To illustrate this, Hennion (2007: 105) provides the example of wine drinking. One can, on the one hand, simply drink wine, without paying attention to its qualities. On the other hand, to pause and linger over the wine, even if only for a moment, means to find, in this moment, a shift of the wine drinker towards the wine. The individual is attentive towards the cultural object, and when this happens, '[t]he object also shifts, advances a notch, to deploy itself and deliver its richesse, involving a more marked contrast and a rising in its presence' (Hennion 2007: 105). In Hennion's account of taste, then, we can see empirical examples of precisely how individuals, through techniques and methods, which are refined and improved, engage with cultural objects.

\section{The sweep of time and the particular moment of aesthetic engagement}

Ori Schwarz (2013) makes the important point that there is a tendency in some of the post-critical approaches to taste (such as Hennion's) towards a denial of the social. Hennion's 'amateurs' 'are not merely "people”: they have strong class characteristics' (Schwarz 2013: 422). Individuals and the tasting techniques they deploy are both social products; tasting techniques, in common with norms of social interaction, are socially acquired (Schwarz 2013: 420). According to Schwarz (2013: 421), critical sociology demonstrates that tastes are durable, relatively stable, and persist across time, across contexts; there are class/status characteristics of tasting techniques; and 
that these techniques are used as a basis for cultural distinction and social closure. A useful suggestion made by Schwarz (2013: 420) is that a sociology attentive to both the critical framework and aesthetic dimensions of taste should choose techniques as the primary objects of study, objectifying these techniques rather than, as does Bourdieu, objectifying tastes. This ensures that the diachronic aspect of aesthetic engagement is heeded as we identify how tasting techniques 'are acquired, applied, reproduced, and changed' (Schwarz 2012: 424). If we rely entirely on the insights produced by some of the proponents of the new sociology of culture, we are left with a historically shallow account of aesthetic value, one that focuses on the synchronic alone. Nick Prior (2011) raises an important question in relation to Hennion's work: with critical insights regarding the social determinants of taste expunged, 'does this mean that we are merely left to describe singular aesthetic moments of attachment?' (Prior (2011: 134). Prior argues the importance of avoiding a de-sociologized account of taste and aesthetic engagement. It is, rather, more productive to synthesize key elements of the critical and post-critical perspectives, as Schwarz (2013: 419-420) suggests, thus 'embedding the aesthetic dimension within the framework of critical sociology'. Prior (2011: 135) argues that we need to deploy Bourdieu's ideas strategically in order to counter overly internalist readings of culture as well as cultural sociologies that give culture too much autonomy'. As I have argued elsewhere, in analyzing subjective, first-hand accounts of taste, 'it is not easy to discount the bodily dispositions associated with the habitus and the resources at our disposal which determine in great part why it is that we are likely to express certain tastes, the ways in which we express our taste and what this says about us' (Stewart 2013b: 100-101). 
I propose, then, that in formulating a sociologically informed approach, we need to consider the intersection of the sweep of time and the particular moment of aesthetic engagement. Starting with the sweep of time, we need to consider the specific histories that bring individuals to the moment of engagement. This is where we strategically deploy Bourdieu, holding on to his key insights about the social construction of taste (Prior 2011). This is precisely where Bourdieu's insights in relation to the temporal dimension of social life remain useful: as he memorably puts it, '[h]abitus is that presence of the past in the present which makes possible the presence in the present of the forth-coming' (Bourdieu 2000: 210). Bourdieu and Wacquant (1992: 127) argue that habitus is 'the social made body'; we carry the past, or more specifically our past and that of our families, in our bodies, in our minds, in the form of internalized dispositions that govern our thoughts and practices. Habitus therefore represents a link between the objective and subjective worlds as individuals internalise external social reality in their bodies in the form of durable, even permanent dispositions. As a consequence, individuals have a practical orientation to reality that is informed by their previous experiences, by their familial, educational and class backgrounds. In sum, we need to understand that even in individuals' momentary, spontaneous engagements with cultural objects, the ways in which they evaluate and the extent to which they refer to formal properties of the objects, or are able to relate these objects to the field(s) of cultural production from which they hail, will be determined, in great part, by social origin, class background, educational background. This does not mean, however, that responses will be entirely determined by these factors, nor does it preclude factors that emerge as a result of affective or contradictory or contrarian impulses that emerge in the course of the moment when, for example, we are impressed by the emotional and seductive power of a film but 
feel a deep repulsion for its representations of gender; when we affirm the quality of a particular cultural object on the basis of its aesthetic properties, while at the same time being unsettled or appalled by the political persuasions of its creator(s); or when we recognize the slickness and sophistication of a sculpture installation but feel, at the same time, dismayed by its tawdriness and its cynicism.

Focusing on the particular moment of aesthetic engagement, and considering this moment alongside many others that have come before, would enable us to see how judgements change as much as how they remain constant and relatively predictable. Furthermore, I suggest, a well-rounded approach to aesthetic value needs to imbue its analysis with specific reference to non-sociological aesthetic criteria, which are neglected in Bourdieu's analysis and which, of course, have their own histories, deriving from 'older' disciplines such as art history and philosophy. Nonsociological aesthetic criteria retain their currency in the justifications of curators, critics, artists and other significant agents in the artistic field (Wolff 2008). Bourdieu's great theoretical insight is to demonstrate that aesthetic properties speak for the particular part of the field of cultural production from which they have emerged. They speak for the particular moment in the history of the cultural field(s) to which they belong (Bourdieu 1993[1983], 1996[1992]). On the other hand though, we need to consider that aesthetic properties are reconfigured, indigenized and glocalized, as they are deployed and decoded in different places (Appadurai 1990; Robertson 1995). So, for example, the aesthetic codes associated with MTV are tailored so that they will accord more readily with the cultural sensibilities of 'local' audiences in different regions of the world (Cho and Chung 2009). An approach that draws attention to the sweep of time, to our histories and the histories of the field allows us to see how our engagements with cultural objects change over time, even as 
the properties of objects are reconfigured. But it needs to intersect with analysis of the particular moment, considering the aesthetic properties of the cultural object and the extent to which individuals fully engage with the object.

Each aesthetic judgement is specific to the moment in which it is articulated. This means, for example, that listening to the same piece of music under different conditions will produce a (slightly or wholly) different appraisal each time. These complications make it more difficult to empirically research aesthetic evaluation but also make it all the more interesting as we seek to trace the dynamics at work and uncover the tacit impulses at play when individuals engage with cultural objects. Considering specific moments of aesthetic engagement will enable us to understand their degree of focus and intensity (Stewart 2012, 2013a, 2013b). In the new sociology of culture, we see (for example) in Hennion's findings (and in similarly oriented work such as Benzecry's $(2009,2011)$ research on opera fans who learn how to maximize their enjoyment of opera and how to evaluate various operatic performances and productions) that aesthetic engagement is often characterized by a deliberative, passionate response to a cultural object. This is very much an example of being swept up in the specific moment: allowing oneself to be carried away (Hennion 2001, 2004, 2007). Hennion's $(2001,2004,2007)$ work can be fruitfully adopted in order to understand acts of engagement that emerge from intense cultural experiences. For example, he argues that music can help us to formulate a theory of passion (Hennion, 2001). However, very often our aesthetic engagements are characterized by a lack of intensity. This is especially so when one considers that many aesthetic engagements occur in environments characterized by ordinariness or familiarity: whether the front room, the bedroom or the roads travelled daily to and from work. Furthermore, rather than emerging out of deliberate, practiced engagement with 
cultural objects which we are predisposed to like, our engagements emerge out of chance (or 'happenstance') encounters with objects. The theoretical model I propose in order to understand the particular moment of engagement distinguishes between sustained and distracted modes of engagement. Whereas sustained engagement refers to a heightened level of concentration and the ability to give one's prolonged attention to a cultural object, distracted engagement occurs when our aesthetic experiences coexist with other activities such as childcare or domestic duties. In this distracted mode, we might attribute value to a cultural object while writing a shopping list or while cleaning the kitchen. Here, we see the banal, everyday aspect of aesthetic engagement, an aspect that might surprise those who presume that aesthetic experience occurs exclusively on a lofty plane. Distracted engagement occurs when we engage simultaneously with one or more aesthetic stimuli as well as when we are multi-tasking. Here, we might carelessly dismiss an image that emerges in our field of vision just as we are ruminating on the merits of a musical piece that drifts through the air as we wander.

\section{Social time and social acceleration}

In order to better understand the temporal dimensions of aesthetic engagement, let us now consider the key sociological concept of social time. This concept can help us understand how people use and possess time during which to engage with cultural objects. In The Elementary Forms of Religious Life, Emile Durkheim (2001[1912]: 11) developed this notion, arguing that the category of time neither inheres in nature nor does it exist as an a priori faculty of the mind. According to Durkheim (2001), the significance of time reaches beyond individual experience because it is held in 
common by the collective and is thus objectively conceived. Therefore, time, alongside notions such as space, genus, number and cause, needs to be understood as a category of understanding that is social in origin, deriving from religious thought and, more specifically, from the division between the sacred time of festivals and the profane time of work. Social time 'expresses a time common to the group ... and is itself a kind of social institution' (Durkheim 2001: 12). Just as, in spatial terms, there is no inherent north or south, left or right, but only notions of space that derive from common understanding, social time is understood collectively.

Pitirim A. Sorokin and Robert K. Merton (1937) argue that a distinction needs to be made between astronomical time (which is quantitative and continuous) and social time (which is qualitatively differentiated according to beliefs and customs held by the collective). Social time is discontinuous and 'expresses the change or movement of social phenomena in terms of other social phenomena taken as points of reference' (Sorokin and Merton 1937: 618). Social time is, as Eviatar Zerubavel (1976: 87) later argued, artificial and based on social conventions. If we go to a concert, we might, therefore, agree to meet with someone 'after the show'; we might refer to an event that took place soon after a particular political leader took office; or we might discuss the sequence of events with reference to whether they took place before, during or after a particular historical event. Along similar lines, we might make arrangements or mark our calendar on the basis of comprehensible time durations such as 'the end of the working day' or 'the length of the semester', both of which refer to social rather than astronomical phenomena (Sorokin and Merton 1937: 619). Time, then, has an intersubjective character, and it is a task for sociologists to study the timetables and scheduling of a given society, the processes that govern the temporal patterns of social life (Zerubavel 1976: 88). It is often only when we take 
'time-off' from our usual schedules, when we go on holiday, for example, that the socially constructed nature of time comes into relief 'as normative temporal structures come into contrast with a more flexible, or altered, approach to time' (Stein 2012: $351)$.

A shared understanding of time is made possible by standard time-orientation, which, according to Zerubavel (1976: 88), consists of 'standard units of duration and a standard system of time reference'. These systems of reference, such as International Standard Time, are based on arbitrary social conventions. Reflecting on this degree of precision and coordination brought about by the money economy and an increasingly complex division of labour, Georg Simmel (1971[1903]: 328) argued that 'the technique of metropolitan life in general is not conceivable without all its activities and reciprocal relationships being organized and coordinated in the most punctual way into a firmly fixed framework of time which transcends all subjective elements'. With so much of our daily lives spent measuring time effectively and living in accordance with calculable, unambiguous, quantitative values, Simmel (1971: 328) invited his reader to imagine the chaos that would ensue in a city like Berlin if all the watches and clocks stopped working. Max Weber (2001[1904]) drew attention to the rationalization of time in his thesis on the spirit of capitalism and in his work on bureaucracy, and his reflections on capitalism and time draw attention to an economic orientation to time that is prevalent in capitalist societies (1968[1913]). Time is considered a scarce resource and it is invested wisely or it is wasted; in private capitalist enterprises and state bureaucracies, its use is optimized and accounted for in a way analogous to rational budgeting. The budget determines the resources that are to be allocated; the time schedule determines the order of priority of the various entitlements (Schwartz 1974: 869; Weber 1968, 2001). Weber (2001) 
argued that the gain spirit associated with capitalism's rise, as typified in the maxims of Benjamin Franklin, is characterized by a relation to time that emphasizes frugality, industry, punctuality and profitability. Furthermore, Weber drew attention to the Puritan-inspired belief that maintains that whereas the prudent use of time was associated with virtue, the tendency to waste time through idleness, play, luxury or excessive sleep was sinful (2001: 104). Even in today's world of global financial capitalism, the continuing relevance of Weber's thesis can be observed, for example, in the culture of presenteeism at investment banks which ensures that one's phone is never switched off; in the willingness on the part of staff in the banking sector to work all hours and renounce annual leave; and in the pressure to avoid taking long vacations (Stein 2012: 348).

As Barry Schwartz (1978: 6) points out, the time-bound nature of social organization is encapsulated in the notion of business (busyness): productive activity that has to be performed swiftly, in a hurry, before it is too late. With social time increasingly measured quantitatively in this way, claims have been made by a number of social theorists that in these late modern times, we are witnessing an acceleration of sociality. This is perceived to be a consequence of (for example) time-space distanciation (Giddens 1990); the information technology-driven compression of time (Lash 2002); technological acceleration (transport, communication, production); the acceleration of social change (with institutional stability in decline); and the acceleration of the pace of life (the speed and compression of activities in everyday life) (Rosa 2003). A common assumption that runs through the social acceleration thesis is that, in contradistinction to the predictions made regarding a technologyenabled post-World War 2 leisure utopia, we are all working more hours than ever 
before; we are increasingly pressed for time; and we are rushed as we move from one commitment to another.

Although data gathered from time use research in the United States of America suggests that people do indeed feel more rushed, there is little empirical evidence to suggest that the majority of people are actually working longer hours (Wajcman 2008). Leisure time is actually increasing for many sectors of the population in Western Europe and North America (Wajcman 2008; Sullivan and Gershuny 2004). Stella Chatzitheochari and Sara Arber's (2012) analysis of UK time use data offers an attempt to provide a sophisticated analysis of time poverty that extends beyond the conventional understanding of this phenomenon: they consider the relative significance of weekday and weekend free-time and the extent to which domestic and childcare duties impinge upon free time. Along similar lines, Judy Wajcman (2008: 64) argues that to account for the perceived increase in the pace of life, one has to consider 'the combined work commitments of family members, rather than the changes in the working time of individuals'. It is important to consider, therefore, not just the duration of working hours but the fact that, for example, women in dual-earner families feel harried by the number of domestic, leisure and workrelated tasks that they have to perform.

\section{Aesthetic engagement in sustained and distracted modes}

Many of us, then, are 'in a rush' as we go about our activities. But it is not that simple: social time is stratified and some are more able than others to possess their time, as time-use research on relative time poverty indicates (Auyero 2010; Chatzitheochari and Arber 2012). For example, though the work-rich are time-poor 
during certain periods, they are more able than those below them in the social scale to enjoy periods of unconstrained free time; they are also more likely to have control over when they work and rest (Chatzitheochari and Arber 2012). As Schwartz's (1974) influential work on waiting time and the distribution of power demonstrates, time is a resource allocated variably, patterned by the distribution of power and wealth. According to Schwartz (1974) control over time is a privilege of power. If we take the example of an exchange situation, for example, where servers are in great demand and are visited by a great number of clients, their exchange position will be enhanced and they will be in a position to take their time. They will be busy but not be reliant on any one particular client; there are many to see. Reflecting on his research on overnight queues for Australian football tickets in Melbourne, Leon Mann (1969) concludes that although the queue as a micro-social system contains elements of cultural egalitarianism and distributive justice, it is populated mainly by working class men who are more likely to need to queue in order to gain access to scarce resources. In contrast, those from more privileged backgrounds are in a position to 'circumvent the line altogether and get their tickets through agencies or other contacts' (Mann 1969: 353). Again, here we see that those with less capital at their disposal are more likely be those who spend more time waiting and have less control over their time. In an ethnographic study of the experience of applicants for welfare benefits in Buenos Aires, Javier Auyero (2010) finds that the claimants are forced to wait interminably, as powerless subjects of the state, in a Kafkaesque trial of patience during which they endure endless delays and arbitrary changes of the rules. The claimants spend great swathes of time in uncomfortable rooms and corridors; they are left to negotiate labyrinthine bureaucracies and endless paperwork only to be delayed and deferred, with decisions adjourned and their hope kept alive only enough to 
prolong the waiting. Here again, waiting is a strategy of power and an instrument of domination (Auyero 2010).

With the stratification of social time in mind, we need to consider two idealtypical modes of aesthetic engagement that correspond to the ability (or otherwise) to possess time. They are sustained and distracted engagement. Sustained engagement refers to the temporal mode that we adopt when we decide to engage, for example, with a painting 'for a while', when we lose track of time engrossed in a film, or when we take the time to contemplate the merits of a wine before sharing our evaluative judgement with others. Sustained engagement is only possible for those who have the time and the option of casting aside all other duties to engage with cultural objects. Sustained engagement requires time for oneself. To some extent, we can all find some such time: whether it is the business executive taking a day off work to go to the opera or the prisoner assessing the value of a novel from her or his cell. Hennion's (2007) research demonstrates that amateurs and not just connoisseurs practise sustained aesthetic engagement. Nevertheless, bound as we are by the social timetables that structure our existence, the experience of sustained engagement in its ideal-typical form can be found only when the opportunity is total and all consuming, where we can take a 'time out' from our lives, and where, during the moments that pass unnoticed, nothing else seems to matter except our appraisal of the cultural object. The intensity attained is often hard to maintain because, for example, in the gallery, other artworks will distract as will the presence of other people; listening to music might block off other sounds, but one's eyes are free to roam, as are one's thoughts. More crucially though, duties call, and for many of us, opportunities to linger and to lose oneself in aesthetic engagement for sustained periods of time are limited. 
As one ascends the social scale, one is more likely to have the time for engagement in its sustained mode and the aesthetic disposition that enables sustained contemplation is the product of a prolonged period of time freed from the need to engage in economic activity (Bourdieu 1984, 2000). Those in control of time are able to possess and occupy the present moment. Value accrues to those who have control over time: they will not only have more time for sustained aesthetic engagement but their pronouncements will be afforded greater weight: they are more likely to be legitimized and consecrated at an institutional level. Holders of cultural titles (for example, those with prestigious higher education-bestowed qualifications) or prominent curators and critics 'only have to be what they are' (Bourdieu (1984: 23) (In contrast, those without such titles are only valued in terms of what they do and their opinions count for little). Their expertise is a power over the present, acquired in the past and projected into the future. Hence it is that the archetypal holder of the aesthetic disposition is in a prime position to engage in sustained engagement: s/he possesses the requisite power to possess the moment and has the time to engage with a purposeful purposelessness for prolonged periods of time. Chatzitheochari and Arber (2012) distinguish between pure free time (free from the need to perform secondary activities) and contaminated free time (where domestic chores or childcare duties spill over into the free time). They find that whereas high earning males have very little free time during the working week, they have greater control over when they work (and, for example, they are freed up at weekends) than low-skilled workers who are more likely to do shift work during unsocial hours (Chatzitheochari and Arber 2012: 467). We might expect to find, then, that high-earning males are more likely than low-skilled workers to be able to find the time for sustained aesthetic engagement. In contrast, working women 'are at a much higher risk of being 
positioned at the bottom of free time distribution on both weekday and weekend days, even after adjusting for socio-economic circumstances' (Chatzitheochari and Arber 2012: 467) and, one would presume, will more likely find that their aesthetic experiences are conducted in distracted mode. This is a consequence of the extent to which their free time is dominated by domestic and family-related chores.

Aesthetic engagement, we might reasonably presume, is more common in its distracted mode. As John Fekete puts it, 'we live, breath, and excrete values. No aspect of human life is unrelated to values, valuations, and validations' (Fekete 1988: i). With value-judgements made on an involuntary basis, we 'excrete them' while we are simultaneously performing other tasks or even while we are considering the merits of other cultural objects. On the axes of possibility then, we might lean more towards sustained engagement when in a cultural milieu that encourages us to pay attention: when in the darkened seating areas of the cinema or theatre, or when listening reverently at a poetry reading. In contrast, our evaluative judgements are more likely to be formulated in distracted mode when we are in multi-tasking situations, when (for example) watching television on the sofa and indulging in 'an evening in' with a loved one; when we are walking down the street swept away by visual stimuli; or when we are listening to music while performing domestic duties.

Walter Benjamin (1968[1936]) does not explicitly discuss matters of aesthetics in 'The Work of Art in the Age of Mechanical Reproduction'. However, there is much that we can learn from this famous essay in relation to aesthetic engagement when performed in distracted mode: when performing other tasks (domestic or childcare duties, while working); when one is scarcely paying attention to the cultural object (the television on in the background, half-listening to music); or when several cultural objects are consumed at once. Benjamin (1968: 221) argued that 
in the burgeoning modern world of mass production, cultural objects are increasingly designed for reproducibility; they are no longer valorized on the basis of their uniqueness. This means that, for example, the cult value associated with unique, irreplaceable art objects such as the Mona Lisa, which only a small number of people can view at any one time, is replaced by the more democratic exhibition value associated with mass-produced cultural objects. Benjamin's model provides a way of understanding aesthetic value and the distracted mode of engagement.

Films, as mass-produced objects, can be viewed simultaneously by a great number of people. They can be reproduced and disseminated without the need for an original copy. As Benjamin (1968: 221) noted, 'that which withers in the age of mechanical reproduction is the aura of a work of art' as a plurality of identical copies takes the place of the unique artwork. The exhibition value that characterizes film consumption is characterized by the fact that the viewer absorbs the 'multiple fragments ... assembled under a new law' (Benjamin, 1968: 234) in an absent-minded manner, rather akin to the ways in which we engage with architecture by use and perception, rather than with the full concentration that would absorb a keen tourist contemplating a famous building (Benjamin, 1968: 240). Benjamin's work has much to tell us in our twenty-first century world, where so many of the cultural objects with which we engage are digitally reproduced and disseminated, and where, with the click (or two) of a button, we can access innumerable cultural objects, whether books, symphonies, images on webpages, graphic novels or computer games. Ours might be a distracted mode of engagement with a piece of music that we hear playing while we perform a domestic task; or we might make evaluative judgements in relation to narrative, character or plot developments in soap operas at the same time as we look after our children. Denise D. Bielby and William T. Bielby's (2004) research on soap 
opera fan communities gives us insight into how audiences draw on a shared understanding of the aesthetic codes and conventions associated with the genre. Fans consider (for example) the plausibility (or otherwise) of a plot-development and the extent to which character development is logically consistent in their favourite programmes. Bielby and Bielby (2004) argue that these aesthetic criteria are referred to casually, 'in the moment' of viewing as well as more formally, in letters, blogs and emails to producers and other fans.

Wajcman (2008: 70) draws attention to how digital technologies and mobile modalities can be used creatively and expediently as people use devices to gain control over their multi-tasking and are expedient in enabling temporal control by, for example, getting tasks done during what would otherwise be 'dead time' (in airport lounges or in waiting rooms) and finding richer ways of communicating with distant others. I suggest that we need to be attentive to the ways in which people use this dead time for distracted (and perhaps also sustained) aesthetic engagement. Far from the austere conditions of the museum or art gallery, the airport lounge (for example) becomes a site for aesthetic contemplation, and very often it is the case that we carry several cultural objects with us as we travel and we anticipate in advance the sheer volume of time that needs to be killed. We might, for example, select a novel on one device and read it while listening to music selected on another. Here, we navigate cultural objects by use and by perception; we accustom ourselves to the various media platforms we utilize, and very often it is the case that for those with access to such resources, simultaneous engagement with a number of cultural objects is possible. We engage with objects in quick succession, and, for example, within several windows on our computer we find music applications, video games, film clips, assorted images, essays and blogs. However, the ability to confidently kill time in the present and rid 
ourselves of 'dead time' is the privilege of those with an ability to anticipate the future. Bourdieu makes the important point that the practical relation to the future, to the forth-coming, depends on the possession of power (in the form of capital) in the present (Bourdieu 2000: 223). For the powerless, especially those out of work, the temporal link between the present and the future is severed: the powerless are more likely to be absent from the meaningful world of timetables and schedules, of duties and tasks, purposes and motivations, investments in the moment and enticements of the future. They are left stranded in a meaningless present, an empty, dead time. Those with low volumes of capital working with little or no job security and earning the minimum wage are at least incorporated in the world of timetables and schedules but their ability to use time fruitfully is constrained by a lack of autonomy and the demands of monotonous, unrewarding labour. Whereas those immersed in 'the game' are so busy that they do not notice time passing, those stuck in dead time or constrained by monotonous labour cannot but notice its presence (Bourdieu 2000: 224). Those with the necessary capitals at their disposal are more able to take control of dead time and have the opportunity to use it for aesthetic purposes. Their time is scarce but its scarcity affords it value. Furthermore, the work-rich, with money to spend but with little time to spend it, can indulge in what Sullivan and Gershuny (2004: 88) term 'inconspicuous consumption', which means that they can procure aesthetic objects that provide the basis for future-oriented fantasy, but which are not displayed. In contrast, for those without such resources, dead time is excessive and valueless but it dominates the horizon.

The notion of distracted aesthetic engagement enables us to see that many interactions with cultural objects take place in an absent-minded manner, producing as a series of micro-evaluations that might seem meaningless when considered in 
isolation but gain significance as part of wider patterns. Engaging with several cultural objects at once we might flick through various webpages, or the pages of eBooks, while perusing visual images, making a series of micro-judgements as we go. Our distracted manner of engagement is coupled with the fact that many such acts of cultural evaluation are fragmentary. For example, we do not necessarily make judgments on the basis of having systematically taken in a book, film or song in its entirety. Rather, we might dismiss a book after ten pages or so; we might halt an irritating song in mid-flow; we might flick restlessly from one film to another, making prickly comments as we do so and expressing mild dissatisfaction. It is equally probable that we will respond favourably to the aesthetic properties of these objects, even if our expressions of approval are expressed in the mildest terms. Here, the evaluative judgments we make probably have more in common with the minor or trivial aesthetic categories referred to by Sianne Ngai (2012), which are characterized by non-cathartic feelings, leading, for example, to irritation rather than to outbursts of anger, and to feelings of mild amusement rather than to the lofty emotions associated with the sublime or the beautiful. These are feelings that arrive one moment and are gone the next. This does not mean, however, that they lack significance.

Attention to the distracted mode of aesthetic engagement enables us to see that we might not even be fully or consciously aware that we are evaluating. More often than not, the evaluative judgements we make in banal, everyday situations are likely to be characterized by relative indifference towards the objects. We might consider A mildly interesting and B moderately worthy of our attention. We might not really care for $\mathrm{C}$ that we have just read, and though we might admit that $\mathrm{D}$ is fairly well-written, as is E, it certainly is not 'up there' alongside F, which set our pulses racing and our minds afire. Along similar lines, when by happenstance we encounter cultural objects 
in the course of our journeys from one part of a city to another, we might moderately enjoy the song played by a busker; we might take some mild pleasure in tracing the bold contours and colours of street art; or we might casually dismiss the tacky qualities of a commodity that is dangled in front of us in the market place. We might be mildly irritated by a street performance that interrupts our thought process and so assess its qualities negatively but without hostility. We need to consider these semiconsciously formulated evaluations alongside those yielded by a sustained mode of aesthetic engagement though tracing them might prove to be more difficult.

\section{Conclusion}

In paving the way for empirical research on this topic, this article considers the relation between aesthetic engagement and time. It draws attention to the particular moment of engagement and the sweep of time that brings us to this moment. It considers aesthetic engagement in its sustained and distracted modes, aware that there are, of course, many modes of engagement that fall between these ideal types. It also draws attention to the stratification of social time and the fact that some are more able than others to possess time and find time for sustained aesthetic engagement. To what ends might such empirical research be directed? Primarily, it will seek to understand how people aesthetically engage with objects across time. Secondarily, it will seek to examine the extent to which evaluative judgements of individuals and groups maintain their shape over time as they engage with cultural objects (each of which have their own histories). Such research will raise a number of subsidiary questions. For example, how significant is the role of whim, contrariness or affect as we decide what we like and dislike (Probyn 2000; Highmore 2010)? What is the impact of 
generational changes in the articulation of our value judgements (Turner and Edmunds 2002)? To what extent are our likes and dislikes reconfigured as a consequence of 'the complex interplay between national, regional and global cultural connections' (Bennett et al. 2009: 249-250)? How do our aesthetic value judgements change as a result of dialogue within the context of communities (Wolff 2008)? Might it be possible that out of seemingly intractable differences, consensus can nevertheless be reached over the course of time and co-authored intersubjective judgements can be observed? Addressing these questions will be by no means straightforward. Eliciting and interpreting data on aesthetic engagement is a complex task whether one is asking respondents to reflect on sustained or distracted modes of engagement. This notwithstanding, in an era during which value is often simply dismissed as a quantitative matter for markets, such research can help us to formulate a stronger understanding of how and what people value across time. 


\section{Bibliography}

Appadurai, A. (1990) 'Disjuncture and Difference in the Global Cultural Economy', Theory, Culture \& Society 7(2): 295-310.

Auyero, J. (2010) 'Chuck and Pierre at the Welfare Office', Sociological Forum 25(4): 851-860.

Becker, H.S. (1982) Art Worlds. California: University of California Press.

Benjamin, W. (1968[1936]) 'The Work of Art in the Age of Mechanical Reproduction', in Illuminations (pp. 217-251). New York: Schocken.

Bennett, T., Savage, M., Silva, E., Warde, A., Gayo-Cal, M., and Wright, D. (2009) Culture, Class, Distinction. London: Routledge.

Benzecry, C. (2009) 'Becoming a Fan: On the Seductions of Opera', Qualitative Sociology 32: 131-151.

Benzecry, C. (2011) The Opera Fanatic: Ethnography of an Obsession. Chicago: University of Chicago Press.

Bielby, D. D., and Bielby, W.T. (2004) 'Audience aesthetics and popular culture', in R. Friedland and J. Mohr (eds.) Matters of Culture: Cultural Sociology in Practice, pp. 295-317. Cambridge: Cambridge University Press.

Bourdieu, P. (1984[1979]) Distinction: A Social Critique of the Judgement of Taste. London: Routledge.

Bourdieu, P. (1990[1980]) The Logic of Practice. Cambridge: Polity Press.

Bourdieu, P. (1993[1983]) The Field of Cultural Production: Essays on Art and Literature. Cambridge: Polity Press.

Bourdieu, P. (1996[1992]) The Rules of Art. Cambridge: Polity Press. 
Bourdieu, P. (2000[1997]) Pascalian Meditations. Cambridge: Polity Press.

Bourdieu, P., and Wacquant, L. (1992) An Invitation to Reflexive Sociology.

Cambridge: Polity Press.

Chatzitheochari, S., and Arber, S. (2012) 'Class, Gender and time poverty: a time-use analysis of British workers' free time resources', The British Journal of Sociology 63(3): 451-471.

Cho, S.H., and Chung, J.Y. (2009) 'We want our MTV: glocalization of cable content in China, Korea and Japan', Critical Arts 23(3): 321-341.

De La Fuente, E. (2008) 'The Art of Social Forms and the Social Forms of Art: The Sociology-Aesthetics Nexus in Georg Simmel's Thought', Sociological Theory 26(4): 344-362.

DeNora, T. (1999) 'Music as a technology of the self', Poetics 27: 31-56.

DeNora, T. (2000) Music in Everyday Life. Cambridge: Cambridge University Press.

Durkheim, E. (2001[1912]) The Elementary Forms of Religious Life. Oxford: Oxford University Press.

Fekete, J. (ed.) (1988) Life after Postmodernism: Essays on Value and Culture.

Basingstoke: Macmillan.

Garnham, N. (1993) 'Bourdieu, the Cultural Arbitrary, and Television', in C.

Calhoun, E. LiPuma \& M. Postone (eds.) Bourdieu: Critical Perspectives, pp. 178-

192. Chicago: Polity Press/University of Chicago Press.

Giddens, A. (1990) The Consequences of Modernity. Cambridge: Polity.

Harrington, A. (2004) Art and Social Theory. Cambridge: Polity Press. 
Hennion, A. (2001) 'Music Lovers: Taste as Performance', Theory, Culture and Society 18(5): 1-22.

Hennion, A. (2004). 'Pragmatics of Taste', in M. Jacobs and N.W. Hanrahan (eds.) The Blackwell Companion to the Sociology of Culture, pp. 131-144. Oxford:

Blackwell.

Hennion, A. (2007) 'Those Things That Hold Us Together: Taste and Sociology', Cultural Sociology 1(1): 97-114.

Highmore, B. (2010) 'Social Aesthetics', in J.R. Hall, L. Grindstaff, and M.C. Lo (eds.) Handbook of Cultural Sociology, pp. 155-163. London: Routledge.

Latour, B. (2005) Reassembling the Social: An Introduction to Actor-Network Theory. Oxford: Oxford University Press.

Lash, S. (2002) Critique of Information. London: Sage.

Mann, L. (1969) 'Queue Culture: The Waiting Line as a Social System', American Journal of Sociology 75(3): 340-354.

Ngai, S. (2012) Our Aesthetic Categories: Zany, Cute, Interesting. Cambridge, MA: Harvard University Press.

Prior, N. (2011) 'Critique and Renewal in the Sociology of Music: Bourdieu and Beyond', Cultural Sociology 5(1): 121-138.

Probyn, E. (2000) Carnal Appetites: FoodSexIdentities. London: Routledge. Rosa, H. (2003) 'Social Acceleration: Ethical and Political Consequences of a Desynchronized High-Speed Society', Constellations 10(1): 3-33. 
Robertson, R. (1995) 'Glocalization: Time-Space and Homogeneity-Heterogeneity', in M. Featherstone, S. Lash, and R. Robertson (eds.) Global Modernities pp. 25-44. London: Sage.

Schwartz, B. (1974) 'Waiting, Exchange, and Power: The Distribution of Time in Social Systems', American Journal of Sociology 79(4): 841-870.

Schwartz, B. (1978) 'Queues, Priorities, and Social Process', Social Psychology 41(1): 3-12.

Schwarz, O. (2013) 'Bending Forward, One Step Backward: On the Sociology of Tasting Techniques', Cultural Sociology 7(4): 415-430.

Simmel, G. (1971[1903]) 'The Metropolis and Mental Life', in D. Levine (ed.) Georg Simmel on Individuality and Social Forms pp. 324-339. Chicago: University of Chicago Press.

Sorokin, P.A., and Merton, R.K. (1937) 'Social Time: A Methodological and Functional Analysis', American Journal of Sociology 42(5): 615-629.

Stein, K. (2012) ‘Time Off: The Social Experience of Time on Vacation', Qualitative Sociology 35: 335-353.

Stewart, S. (2012) 'Reflections on Sociology and Aesthetic Value', Distinktion: Scandinavian Journal of Social Theory 13(2): 153-167.

Stewart, S. (2013a) 'Evaluating Culture: Sociology, Aesthetics and Policy', Sociological Research Online 18(1).

Stewart, S. (2013b) A Sociology of Culture, Taste and Value. Basingstoke: Palgrave Macmillan.

Sullivan, O., and Gershuny, J. (2004) 'Inconspicuous consumption: work-rich, timepoor in the liberal market economy', Journal of Consumer Culture 4(1): 79-100. 
Turner, B. S., and Edmunds, J. (2002) 'The Distaste of Taste: Bourdieu, Cultural Capital and the Australian Postwar Elite', Journal of Consumer Culture 2(2): 219240.

Wajcman, J. (2008) 'Life in the fast lane? Towards a sociology of technology and time', The British Journal of Sociology 59(1): 59-77.

Weber, M. (1968[1913]) Economy and Society. Berkeley: University of California Press.

Weber, M. (2001[1904]) The Protestant Ethic and the Spirit of Capitalism. London: Routledge.

Wolff, J. (2008) The Aesthetics of Uncertainty. New York: Columbia University Press.

Zerubavel, E. (1976) 'Timetables and Scheduling: On the Social Organization of Time', Sociological Inquiry 46(2): 87-94. 